\title{
Nonoperatively treated type A spinal fractures: mid-term versus long-term functional outcome
}

\author{
R. B. Post • C. K. van der Sluis • V. J. M. Leferink • \\ P. U. Dijkstra $\cdot$ H. J. ten Duis
}

Received: 29 February 2008 / Revised: 22 April 2008 / Accepted: 23 April 2008 / Published online: 12 June 2008

(C) The Author(s) 2008

\begin{abstract}
This study focuses on the mid-term (four years) and long-term (ten years) functional outcome of patients treated nonoperatively for a type A spinal fracture without primary neurological deficit. Functional outcome was measured using the visual analogue scale spine score (VAS) and the Roland-Morris disability questionnaire (RMDQ). The 50 patients included were on average 41.2 years old at the time of injury. Four years post injury, a mean VAS score of 74.5 and a mean RMDQ score of 4.9 were found. Ten years after the accident, the mean VAS and RMDQ scores were 72.6 and 4.7, respectively (NS). No significant relationships were found between the difference scores of the VAS and RMDQ compared with age, gender, fracture sub-classification, and time between measurements. Three $(6 \%)$ patients had a poor long-term outcome. None of the patients required surgery for late onset pain or progressive neurological deficit. Functional outcome after a nonoperatively treated type A spinal fracture is good, both four and ten years post injury. For the group as a whole, four years after the fracture a steady state exists in
\end{abstract}

R. B. Post $\cdot$ C. K. van der Sluis $(\bowtie) \cdot$ P. U. Dijkstra Centre for Rehabilitation, University Medical Centre Groningen, P.O. Box 30.001, 9700 RB Groningen, The Netherlands e-mail: c.k.van.der.sluis@rev.umcg.nl

C. K. van der Sluis

Share Graduate School for Health Care Research,

University of Groningen,

Groningen, The Netherlands

V. J. M. Leferink

Department of Surgery, Alysis Health Care Organization,

Zevenaar Hospital,

Zevenaar, The Netherlands

H. J. ten Duis

Department of Surgery, University Medical Centre Groningen, Groningen, The Netherlands functional outcome, which does not change for ten years at least after the fracture.

Résumé Cette étude va pour but de se focaliser sur les résultats à moyen terme (4 ans) et à long terme (10 ans) du devenir fonctionnel des patients traités orthopédiquement pour une fracture de type A du rachis sans déficit neurologique. Méthode:le devenir fonctionnel a été mesuré en utilisant une échelle visuelle analogique (VAS) et le score RMDQ Roland-Morris. Résultats: les 50 patients inclus avaient un âge moyen de 41,2 ans au moment du traumatisme. 4 ans après l'accident, le score douleur VAS était de 74,5 avec un score moyen RMDQ à 4,9. 10 ans après l'accident les scores VAS et RMDQ sont respectivement de 72,6 et 4,7. Il n'existe pas de relation significative entre le score VAS et le score RMDQ ni d'autre part avec l'âge et le sexe ainsi que de la classification de la fracture. 3 patients $(6 \%)$ ont eu un mauvais résultat à long terme. Aucun patient n'a nécessité une reprise chirurgicale ou présentait un déficit neurologique progressif. En conclusion: le devenir fonctionnel des fractures du rachis de type A traitées orthopédiquement est bon à 4 ans aussi bien qu'à 10 ans. Pour ce groupe de patients leur statut à 4 ans n'a pas évolué sur le plan fonctionnel, après une nouvelle évaluation, 10 ans après le traumatisme.

\section{Introduction}

The type A spinal fracture, according to the comprehensive classification (CC), is the most common type of spinal fracture, usually presenting without neurological deficit [13]. This type of fracture is characterised by compression of the vertebral body without injury to the posterior ligamentous complex and in the absence of sagittal translation [13]. Type A fractures are often treated nonoperatively. A large amount 
of literature is available concerning radiological results and short-term results of these fractures. Besides radiological results, an issue of great importance is the functional outcome of these patients. Little is known about functional outcome after type A spinal fractures [18, 19, 21]. Most of the published data concentrate on relatively short-term results (one year follow-up). Literature regarding long-term outcome (ten years and more) is scarce $[8,19,26]$. One might expect increasing pain over time due to altered facet joint motion and hyperextension of adjacent spinal regions, leading to ongoing degenerative processes $[15,25]$. Furthermore, fatigue pain from the soft tissues surrounding the spinal misalignment and the injured disc may be of influence on back pain in the long term [3]. Even late onset neurological deficit may occur years after the trauma, demanding operative intervention $[4,25]$. As such, more information on long-term functional outcome after spinal fractures is needed to understand the problems patients may be confronted with years after a spinal fracture. In this article the mid-term (four years) and long-term (ten years) functional outcome is described from a consecutive cohort of patients treated nonoperatively for type A (A1.1-A3.2) spinal fractures without primary neurological deficit.

\section{Methods}

\section{Patients}

Patients aged between 18 and 60 without primary neurological deficit who were treated nonoperatively for a type A thoracolumbar (T6-L5) spinal fracture (according to the comprehensive classification [13]) at the University Medical Centre Groningen, the Netherlands, were eligible for the study. All patients were treated between 1993 and 2000. Exclusion criteria were previous spinal disorders in the medical history, psychiatric illnesses, pathological fractures, and insufficient command of the Dutch language. Only patients who had taken part in our previous studies and whose midterm outcome was known were included [17, 18]. Patients were sent a letter requesting their participation along with two questionnaires for completion. Medical files of all included patients were reviewed to obtain data on late onset pain and late onset neurological deficits.

\section{Treatment}

Treatment was initialised in our hospital and continued in the outpatient clinic or in a rehabilitation centre. A senior staff member was responsible for deciding on the preferred method of therapy. Treatment consisted of two to six weeks bed rest (or strykerframe). After this period, type A1.3, A2, and A3 fractures were braced and type A1.1 and A1.2 fractures were treated without brace. However, depending on the severity of pain, some type A1.1 and A1.2 fractures were treated without bed rest, by direct mobilisation without brace.

Patients were mobilised with the guidance of a physiotherapist or occupational therapist. Three months post injury weight bearing exercises were introduced. The brace was worn for nine months - the first six months night and day, the last three months only during the daytime.

\section{Functional outcome}

Functional outcome was measured using two disease-specific questionnaires: the visual analogue scale spine score (VAS) and the Roland-Morris disability questionnaire (RMDQ) [10, 20].

The VAS, developed for use in patients with a spinal fracture, consists of 19 items. The patients rate their functional outcome on $10 \mathrm{~cm}$ visual scales. As such, the patient's perception of restriction in activities due to back problems is measured. Higher scores represent better results, which are converted to percentages of the maximum score $(0-100)$. In previous studies, the VAS spine score has proven to be a reliable and valid instrument [10, 17-19].

The RMDQ measures restrictions in activities due to back pain. Twenty-four statements concerning back-related activities are marked as positive (restricted) or negative (not restricted). Scores can vary from zero to 24 , a lower score indicating less impairment [20]. The RMDQ was found to be a sensitive, reliable, and valid instrument for measuring physical impairment due to back pain [22].

\section{Statistical analysis}

Statistical analysis was carried out using SPSS 11.0 (SPSS Inc., Chicago, Illinois). VAS and RMDQ scores four and ten years after the trauma were compared by means of the paired-sample $t$ test. To analyse the effect of independent variables (i.e. age, gender, fracture type, and duration of time between measurements) on VAS and RMDQ difference scores (i.e. mid-termlong-term), a linear regression analysis was performed. A $p$ value of 0.05 was considered to be of statistical significance.

\section{Results}

Patients

Sixty-two patients had taken part in preceding studies and their mid-term functional outcome was known. From these 62 patients, seven were lost to follow-up and five patients refused to take part for a variety of reasons. Fifty patients (81\%) returned the questionnaires and comprised the study group.

The study group ( $n=50)$ consisted of $31(62 \%)$ men and 19 (38\%) women. Mean age at the time of injury was 41.2 years 
(SD 12.0; range 19-60 years). Mean follow-up time for the mid-term functional outcome was 4.3 years (SD 1.7; range 27 years) and for the long-term 9.8 years (SD 2.0; range 714 years). Fracture levels ranged from T6 to L5, 67\% occurred at the thoracolumbar junction (T12-L1). Eight patients $(16 \%)$ had two or more spinal fractures. Of these, only the most severe fracture type was registered and the other fracture was not taken into account. Fracture types according to the comprehensive classification are shown in Table 1 [13].

Aetiological factors were traffic accidents $(n=17)$, accidental falls $(n=23)$, sports accidents $(n=6)$, and occupational injuries $(n=4)$. None of the patients required surgery for late onset pain or late development of neurological deficit.

No differences were found between respondents and nonrespondents concerning age, gender, fracture type, or followup time.

\section{Functional outcome}

No significant differences were found between VAS and RMDQ scores at mid- and long-term follow-up ( $p=0.291$ and $p=0.733$, respectively). The mean difference scores of the VAS and RMDQ were 1.9 and 0.2 , respectively (see Table 2 ).

Three patients $(6 \%)$ had a significantly higher RMDQ score at the long-term assessment. Two of them (patients one and two) displayed a RMDQ difference score of -13 (along with a VAS difference score of +9 and -4 ) (see Fig. 1). In box plots, cases which are outside the box by more than 1.5 times the interquartile range (interquartile range $=3$ rd quartile -1 st quartile) are outliers [24]. As such, these two patients are considered outliers. The third patient (patient three) showed a RMDQ difference score of -8 (VAS difference score +17 ) and could also be considered as an outlier (see Fig. 1). Characteristics of these three patients will be described in the Discussion section. None of these three patients differed significantly from the study group with regard to age, gender, follow-up time, or type of fracture.

Regression analysis with VAS and RMDQ difference scores as dependent variables showed no correlation with age at the time of injury, gender, fracture classification, and time between measurements.

Table 1 Fracture types according to the comprehensive classification $(n=50)$ [13]

$n$ absolute number of patients
Table 2 Outcome and difference scores

\begin{tabular}{|c|c|c|c|c|c|c|}
\hline & \multicolumn{2}{|c|}{$\begin{array}{l}\text { Mid-term } \\
\text { outcome }\end{array}$} & \multicolumn{2}{|c|}{$\begin{array}{l}\text { Long-term } \\
\text { outcome }\end{array}$} & \multicolumn{2}{|c|}{$\begin{array}{l}\text { Difference } \\
\text { scores }\end{array}$} \\
\hline & VAS & RMDQ & VAS & RMDQ & VAS & RMDQ \\
\hline Mean & 74.5 & 4.9 & 72.6 & 4.7 & 1.9 & 0.2 \\
\hline Median & 82.0 & 4.5 & 74.0 & 2.5 & 1.6 & 0.0 \\
\hline $\begin{array}{l}\text { Standard } \\
\text { deviation }\end{array}$ & 21.2 & 4.6 & 22.0 & 5.4 & 13.1 & 4.1 \\
\hline Range & $23-100$ & $0-17$ & $14-98$ & $0-21$ & $-23-25$ & $-13-8$ \\
\hline
\end{tabular}

\section{Discussion}

Approximately $66 \%$ of spinal fractures can be classified as being type A fractures. Of those, $86 \%$ present without neurological deficits [13]. Often, these fractures are treated nonoperatively. Consequently, nonoperatively treated type A spinal fractures form the large majority of spinal fractures. This retrospective, cross-sectional study was conducted to assess long-term functional outcome after nonoperatively treated type A spinal fractures.

Our data show good results at both four years as well as ten years after the fracture. Functional outcome as measured by the VAS and RMDQ appears good at both measurements. A VAS score of 73-75 can be interpreted as an admirable figure. Furthermore, an average RMDQ score of 5 reflects almost no disability; compared to a healthy reference group (VAS score 92-93, RMDQ score of 0.5), patients are only slightly impaired $[10,17]$. When considering these numbers, however, it should be kept in mind that patients with primary neurological deficit were not included in this study. It is well

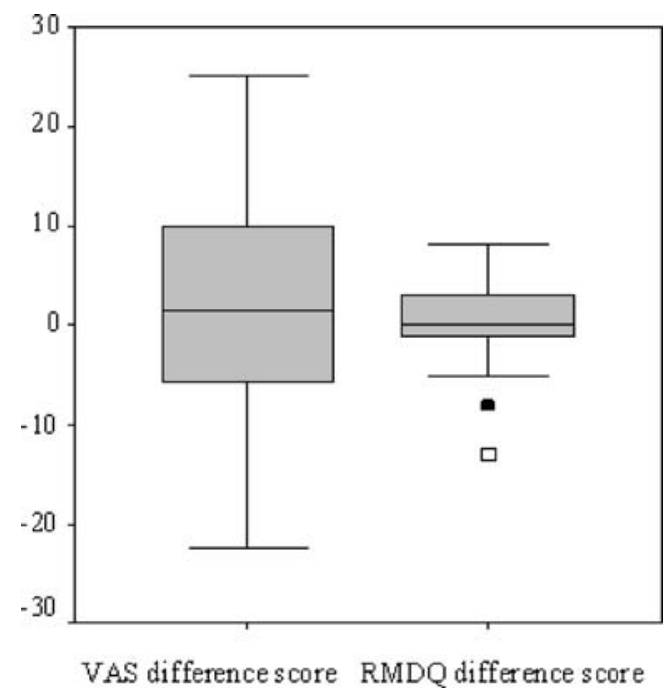

Fig. 1 Box-plot graph showing the VAS and RMDQ difference scores. The graph illustrates the median (inner black line), the upper and lower quartiles (the box), the range of data falling within $1.5 \times$ interquartile range (the whiskers), and outliers ( $\square$ patients one and two, - patient three) 
known that neurological injury negatively affects functional outcome in patients with a spinal fracture [14]. Our results using the RMDQ are similar to that of Siebenga et al. who investigated functional outcome seven years after nonoperatively treated type A spinal fractures; an average RMDQ score of 4.6 was found [21]. A study concerning functional outcome 16 years after nonoperatively treated type A spinal fractures reported a mean VAS score of 58 points [19]. Our results concerning VAS scores are more favourable. An explanation might be that in the aforementioned paper the study group comprised some neurologically injured patients. Recently a VAS score of 67 was found five years after nonoperative treatment for type A fractures [5]. Our mid-term VAS score is to some extent comparable. Tezer et al. as well as Butler et al. [6, 23] also found satisfactory results six years after nonoperative treatment of compression and "burst" fractures, similar to our results. Weinstein et al., as one of the first to study of functional outcome after spinal fractures, found a mean RMDQ score of 13 , measured 20 years after nonoperatively treated "burst" fractures [26]. Our results seem better; a clarification might be found in the fact that Weinstein's paper included patients with neurological deficit and that the fracture classification and distribution was dissimilar to our data.

No difference was found between functional outcome at the mid- and long-term assessments. Furthermore, the time between the two measurements did not show a correlation with VAS and RMDQ difference scores. This indicates that a "steady state" on a group level exists from (at least) four to ten years post injury. Previous studies mention a status quo in functional outcome ranging from two to four years after a spinal fracture [1, 7]. Data on the course of outcome after two to four years, however, are not available. To our knowledge, there is no previously published paper available studying the course of functional outcome after a spinal fracture in the same cohort.

As mentioned before, pain and neurological deficit can arise long after a spinal fracture (mostly after nonoperative treatment, but rarely after operative treatment) [25]. In these cases, operative treatment might be necessary $[4,25]$. Late onset pain requiring operative interference has also been reported for type A fractures [3]. In our series however, none of the patients required surgery for late neurological symptoms or pain. Three patients had a higher RMDQ score at the longterm assessment (difference scores -13 and -8 ), indicating more impairment. Since the minimal clinically important change for the RMDQ is 3.5 points, the alteration in RMDQ scores in these patients indicates a clinically important change [16]. When looking closer at these patients, none of them had a significantly different gender, age, follow-up time, or fracture type compared to the rest of the study group.

Patient one, a 44-year-old woman, sustained a type A1.2 fracture of T12 due to a car accident in 1999. She was treated

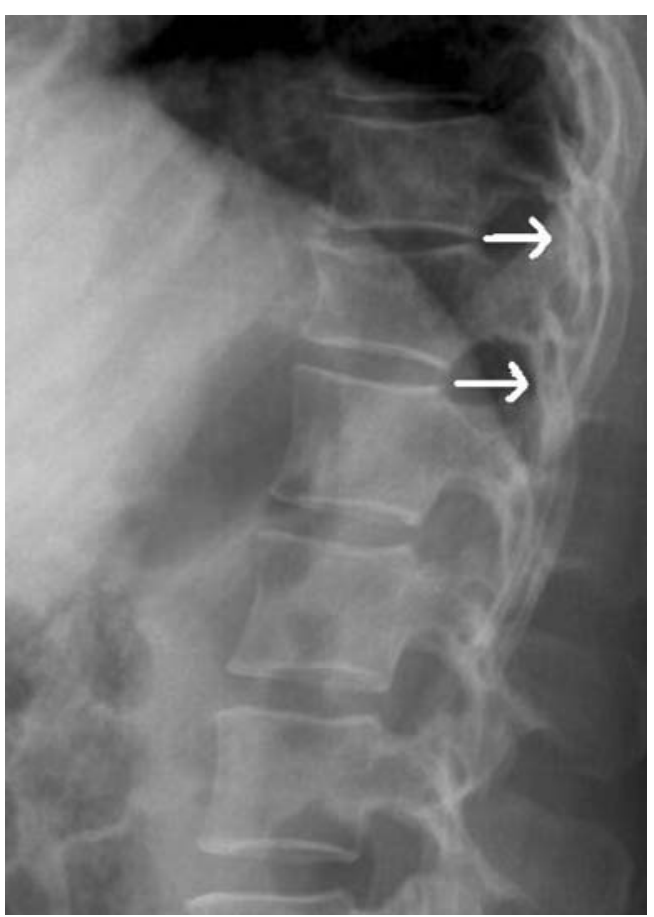

Fig. 2 Radiograph of a T12 fracture (type A1.2) in a 44-year-old woman, three years post injury, showing facet joint arthritis (indicated by arrows)

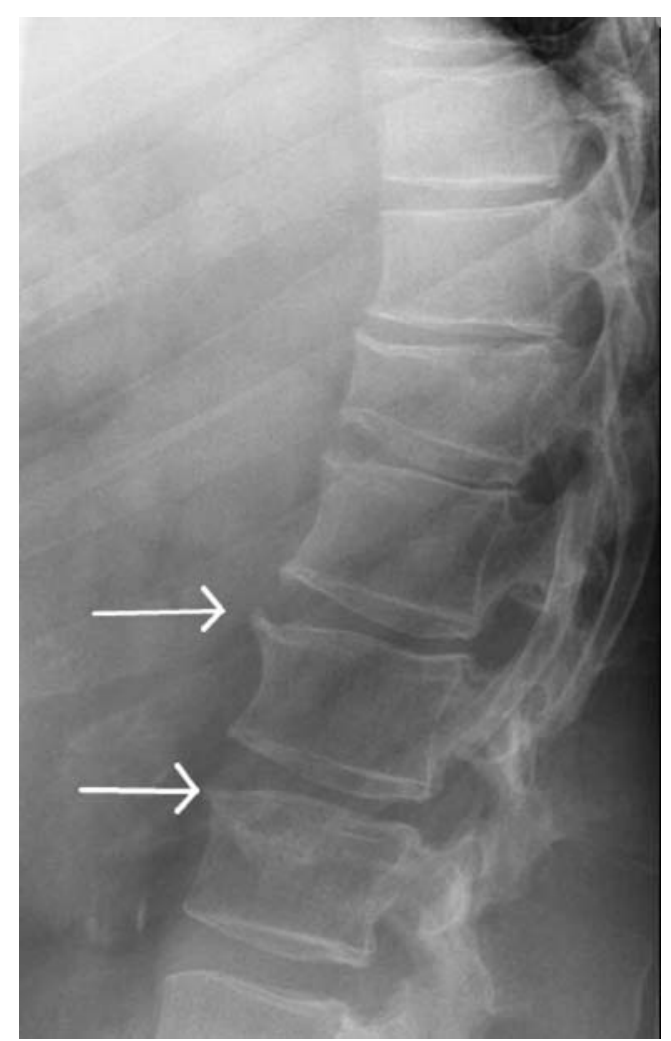

Fig. 3 Radiograph of the type A1.2 T12 fracture in a 44-year-old male, seven years post injury, showing spondylosis at L2-L3 (indicated by arrows) 
by direct mobilisation without brace. At the mid-term measurement (three years post injury) she had a RMDQ score of 7 and a VAS score of 23. At the long-term follow-up (8.1 years post injury), a RMDQ score of 20 was found and a VAS score of 14. After the regular clinical control visits, she never contacted us concerning severe pain. Her general practitioner had requested an X-ray in 2002 since the patient suffered from back pain (see Fig. 2). This X-ray showed osteoarthritis in the facet joints, which could explain her complaints. On the other hand, her VAS score had deteriorated 9 points, which is less than 20 points, the minimal clinically important change when using a VAS [16].

The second patient was a 44-year-old man, who had sustained a T12 fracture in 1997, type A1.2, due to a fall. He was treated by two weeks of bed rest followed by a brace. At the mid-term measurement (5.4 years post injury) he had a RMDQ score of 8 and a VAS score of 23. At the long-term follow-up (10.3 years post injury), a RMDQ score of 21 and a VAS score of 27 were found. After the regular follow-up visits, the patient was seen by a neurologist in 2004 because of low back pain and a strange feeling in both legs. No pathological neurological conditions were found. An X-ray showed spondylosis at L2-L3 (see Fig. 3). This could explain the patient's discomfort.

The third patient was a 38-year-old male, who sustained a type A1.1 fracture of L3 in 2000 following a sports accident. In addition, he sustained a femoral fracture and an acetabulum fracture. The femoral fracture was treated by intramedullary nailing, the acetabulum fracture was treated nonoperatively. At the mid-term measurement (2.1 years post injury) he had a RMDQ score of 0 and a VAS score of 89. At the long-term follow-up (7.3 years post injury), a RMDQ score of 8 and a VAS score of 72 were found. Why this patient deteriorated is unknown.

Given the favourable outcomes found in our series, nonoperative treatment is an appropriate approach for type A spinal fractures without primary neurological deficit. Three patients however, had poor outcomes, although their fractures were classified as being the rather "simple" type A1.1 and A1.2. Why these patients had poor outcomes is unknown. As we made no MRI scans at that time, potential posterior ligamentous complex (PLC) injuries cannot be excluded. The PLC is important in maintaining stability in the spinal column, and rupture may result in instability and severe back pain [15, $23,25]$. As reported by Leferink et al., 30\% of type A fractures (classified on $\mathrm{CT}$ images) appeared to be type $\mathrm{B}$ fractures (PLC lesions present) during operation [12].

We could not demonstrate a relationship between VAS and RMDQ difference scores compared to age, gender, fracture type, or time between measurements. Since no correlation was found between outcome and sub-classification, it is open to discussion whether such an extensive classification as the $\mathrm{CC}$ is required in daily practice. Perhaps there is need for a new, less extensive classification system, which gives more direction to treatment and uses MRI for detecting PLC injuries. The thoracolumbar injury classification and severity score (TLICS), as recently developed by the Spine Trauma Study Group, recognises the aforementioned criteria; possibly it will replace the $\mathrm{CC}$ in the future [11].

This study is subject to certain restrictions and limitations that are worth mentioning. When assessing outcome ten years after a fracture, scores on the questionnaires might be influenced by back pain unrelated to the spinal fracture. For example, pain may arise solely due to the normal process of ageing and osteoarthritis, not per se at the level of the injured vertebra. Furthermore, it is known that a variety of other factors, which we did not consider (e.g. chronic illness, lower education level) might influence back pain [9]. Finally, the small sample size might have introduced a type 2 statistical error [2].

\section{Conclusions}

Functional outcome after a nonoperatively treated type A spinal fracture is good, both at four as well as ten years post injury. Patients are only slightly disabled. For the group as a whole, four years after the fracture a steady state exists in functional outcome, which does not change systematically for at least ten years after the fracture. A small number of patients have a poor outcome, though none of our patients required surgery for late onset pain or late onset neurological deficit. Further research in this group of patients is advocated to reveal contributing factors.

Open Access This article is distributed under the terms of the Creative Commons Attribution Noncommercial License which permits any noncommercial use, distribution, and reproduction in any medium, provided the original author(s) and source are credited.

\section{References}

1. Andress HJ, Braun H, Helmberger T, Schurmann M, Hertlein H, Hartl WH (2002) Long-term results after posterior fixation of thoraco-lumbar burst fractures. Injury 33:357-365

2. Bailey CS, Fisher CG, Dvorak MF (2004) Type II error in the spine surgical literature. Spine 29:1146-1149

3. Been HD, Poolman RW, Ubags LH (2004) Clinical outcome and radiographic results after surgical treatment of post-traumatic thoracolumbar kyphosis following simple type A fractures. Eur Spine J 13:101-107

4. Bohlman HH, Kirkpatrick JS, Delamarter RB, Leventhal M (1994) Anterior decompression for late pain and paralysis after fractures of the thoracolumbar spine. Clin Orthop Relat Res 300:24-29

5. Briem D, Behechtnejad A, Ouchmaev A, Morfeld M, SchermellehEngel K, Amling M, Rueger JM (2007) Pain regulation and healthrelated quality of life after thoracolumbar fractures of the spine. Eur Spine J 16:1925-1933 
6. Butler JS, Walsh A, O'Byrne J (2005) Functional outcome of burst fractures of the first lumbar vertebra managed surgically and conservatively. Int Orthop 29:51-54

7. Chow GH, Nelson BJ, Gebhard JS, Brugman JL, Brown CW, Donaldson DH (1996) Functional outcome of thoracolumbar burst fractures managed with hyperextension casting or bracing and early mobilization. Spine 21:2170-2175

8. Folman Y, Gepstein R (2003) Late outcome of nonoperative management of thoracolumbar vertebral wedge fractures. J Orthop Trauma 17:190-192

9. Harris IA, Young JM, Rae H, Jalaludin BB, Solomon MJ (2007) Factors associated with back pain after physical injury: a survey of consecutive major trauma patients. Spine 32:1561-1565

10. Knop C, Oeser M, Bastian L, Lange U, Zdichavsky M, Blauth M (2001) Entwicklung und Validierung des VAS-Wirbelsäulenscores. Unfallchirurg 104:488-497

11. Lee JY, Vaccaro AR, Lim MR, Öner FC, Hulbert RJ, Hedlund R, Fehlings MG, Arnold P, Harrop J, Bono CM, Anderson PA, Anderson DG, Harris MB, Brown AK, Stock GH, Baron EM (2005) Thoracolumbar injury classification and severity score: a new paradigm for the treatment of thoracolumbar spine trauma. J Orthop Sci 10:671-675

12. Leferink VJM, Zimmerman KW, Veldhuis EFM, ten Vergert EM, ten Duis HJ (2002) Classificational problems in ligamentary distraction type vertebral fractures: $30 \%$ of all B-type fractures are initially unrecognised. Eur Spine J 11:246-250

13. Magerl F, Aebi M, Gertzbein SD, Harms J, Nazarian S (1994) A comprehensive classification of thoracic and lumbar injuries. Eur Spine J 3:184-201

14. McLain RF (2004) Functional outcomes after surgery for spinal fractures: return to work and activity. Spine 29:470-477

15. Öner FC, van Gils APG, Faber JAJ, Dhert WJA, Verbout AJ (2002) Some complications of common treatment schemes of thoracolumbar spine fractures can be predicted with magnetic resonance imaging: prospective study of 53 patients with 71 fractures. Spine 27:629-636

16. Ostelo RW, de Vet HC (2005) Clinically important outcomes in low back pain. Best Pract Res Clin Rheumatol 19:593-607

17. Post RB, Leferink VJM (2004) Sagittal range of motion after a spinal fracture: does ROM correlate with functional outcome? Eur Spine J 13:489-494

18. Post RB, Keizer HJE, Leferink VJM, van der Sluis CK (2006) Functional outcome 5 years after non-operative treatment of type A spinal fractures. Eur Spine J 15:472-478

19. Reinhold M, Knop C, Lange U, Bastian L, Blauth M (2003) Nichtoperative Behandlung von Verletzungen der thorakolumbalen Wirbelsäule. Klinische Spätergebnisse nach 16 Jahren. Unfallchirurg 106:566-576

20. Roland M, Morris R (1983) A study of the natural history of back pain. Part I: development of a reliable and sensitive measure of disability in low-back pain. Spine 8:141-144

21. Siebenga J, Segers MJ, Elzinga MJ, Bakker FC, Haarman HJ, Patka P (2006) Spine fractures caused by horse riding. Eur Spine J $15: 465-471$

22. Stratford PW, Binkley JM, Riddle DL, Guyatt GH (1998) Sensitivity to change of the Roland-Morris back pain questionnaire: part 1. Phys Ther 78:1186-1196

23. Tezer M, Erturer RE, Ozturk C, Ozturk I, Kuzgun U (2005) Conservative treatment of fractures of the thoracolumbar spine. Int Orthop 29:78-82

24. Tukey JW (1977) Exploratory data analysis. Addison-Wesley, Reading, MA, pp 39-43

25. Vaccaro AR, Silber JS (2001) Post-traumatic spinal deformity. Spine 26:S111-S118

26. Weinstein JN, Collalto P, Lehmann TR (1988) Thoracolumbar "burst" fractures treated conservatively: a long-term follow-up. Spine 13:33-38 